\title{
All you can drink: should we worry about quality?
}

\section{Daniel Flores}

\begin{abstract}
All you can drink" specials are forbidden by law in several places. Authorities claim that establishments tend to offer low quality drinks when they use this type of promotion. In this paper, I elaborate a model to determine whether a monopolist produces higher or lower quality goods when using buffet pricing (all you can drink) instead of a two-part tariff. I find that the more profitable strategy is usually associated with a higher quality good than the less profitable strategy. However, under certain conditions buffet pricing is more profitable and leads to lower quality goods than the alternative.
\end{abstract}

Keywords Drinks · Buffet · Two-part tariff · Quality

JEL Classification D42

\section{Introduction}

Some bars and night clubs charge customers a fixed fee to let them consume an unlimited amount of drinks. For example, the hotel chain, Embassy Suites, offers unlimited drinks for a limited period of time in early evening. This pricing strategy, usually advertised as "all you can drink", is forbidden by law in several places. For example, this is the case in Mexican states like Baja California Sur, Querétaro and Zacatecas. Among other reasons, authorities claim that establishments that sell alcohol tend to

D. Flores $(\bowtie)$

Facultad de Economía, Universidad Autónoma de Nuevo León, Loma Redonda 1515 Pte. Col. Loma Larga, 64710 Monterrey, NL, Mexico

e-mail: danflore_mx@yahoo.com.mx 
offer low quality drinks when they use this type of promotion. ${ }^{1}$ However, as far as I know, no formal analysis has been conducted to support this statement.

An "all you can drink" special is equivalent to buffet pricing, which is defined by Nahata et al. (1999) as the practice of charging customers a fixed entry fee and letting them consume an unlimited amount during certain period of time. Although the word buffet is usually associated to restaurants while "all you can drink" is related to bars and night clubs, this pricing strategy and two-part tariffs are widely used in other industries. For instance, some telephone companies offer unlimited local calls for a fixed monthly fee, while others charge a fixed monthly fee in addition to a per-unit price. Transportation services like taxis usually charge a fixed fee when the customer gets into the vehicle and an additional charge related to the distance or time the trip takes. On the other hand, buses usually charge a fixed amount regardless of time or distance.

Although it is not obvious, there is a link between the theory of clubs and buffet pricing. The theory developed by Buchanan (1965) studies consumption-ownership arrangements of a common facility. The basic idea is to determine the optimal number of persons that can share the benefits and costs of a semipublic good. On the other hand, buffet or access pricing is one of the methods more frequently used to charge for semipublic goods. For instance, Barro and Romer (1987) say that ski areas only use this type of pricing.

According to Barro and Romer (1987), a uniform price, a two-part tariff or buffet pricing can be equivalent if there are quantity constraints. In the case of ski-lift facilities or amusement parks, the authors explain that each consumer does not face an explicit constraint but congestion imposes an implicit constraint. A similar situation takes place at bars and restaurants. In this sense, there is no way to determine which of the alternative pricing methods is more profitable. However, the differences in costs associated to each of these methods can make one of them more attractive than the others.

In this paper, I elaborate a model to determine whether a monopolist produces higher or lower quality goods when using buffet (all you can drink) pricing instead of a two-part tariff. The model builds on the work of Nahata et al. (1999) who compare a two-part tariff with buffet pricing, finding that transaction and production costs are crucial to determine which of them is more profitable. According to these authors, buffet pricing is attractive for the firm because it reduces transaction costs. For example, in restaurants there is no need to have waiters taking orders, serving foods and calculating bills. However, customers tend to eat more when they pay buffets than paying for each unit they consume. Thus buffet pricing generates more consumption, which in turn leads to higher production costs.

It turns out that transaction and production costs are again crucial to determine whether a monopolist produces higher or lower quality goods when using buffet pricing instead of a two-part tariff. On the one hand, the monopolist offers are higher quality product when using buffet pricing instead of the alternative if transaction costs

\footnotetext{
1 One of the main reasons to ban "all you can drink" specials is simply to reduce alcohol consumption. However, it is common to find an argument in alcohol laws about the importance of avoiding low quality drinks in the article that bans "all you can drink" specials.
} 
are relatively high in comparison to production costs. On the other hand, it offers a lower quality product if transaction costs are relatively low. This implies that the more profitable strategy is usually associated with a higher quality good than the less profitable strategy.

The intuition behind this result is simple. Firms use a two-part tariff or buffet pricing instead of a uniform price because these pricing strategies allow them to extract at least some part of consumer's surplus. By definition, a high quality good generates more surplus than a low quality good. It follows that a firm has more incentives to increase quality when it uses the pricing strategy that extracts more surplus and, consequently, generates more profits.

Since profits drive the pricing strategy decision, it follows that regulators should not worry about quality most of the times. However, under certain cost conditions buffet pricing is more profitable and leads to lower quality goods than a two-part tariff. Although this result suggests that we should be concerned about quality when a monopolist uses buffet pricing, forbidding this practice is not necessarily a solution to the low quality problem. Indeed, in certain cases it can have the opposite effect.

The remainder of the paper is organized as follows. In Sect. 2, I present background information on quality regulation. In Sect. 3, I define and solve the model considering separately a buffet pricing monopolist and a two-part tariff monopolist that serves one consumer type. In Sect. 4, I compare profits and product quality choices under the two pricing strategies. In Sect. 5, I extend the model to consider two consumer types. Finally, in the last section I summarize the main results of this analysis.

\section{Quality regulation}

The literature about the economics of quality regulation builds on the early work of Oi (1973) and Sheshinski (1976) who take two different approaches. On the one hand, Oi analyzes regulation in regard to product safety. In particular, this author studies the effect of imposing liability on producers over the sale of hazardous products. On the other hand, Sheshinski studies the effects of regulation on the incentives that a monopolist has to provide the socially efficient level of quality.

Although it is possible to find some studies like Besanko et al. (1987) in regard to the provision of efficient levels of quality, most of the recent work is closer to the approach of Oi. In this sense, Weisman (2005) says that regulators are more concerned about quality deterioration as a result of regulation than with firms supplying inefficient levels of quality. In addition, Anderson and Enomoto (1987) explain that the role of regulatory agencies assumed in the recent literature on quality regulation is safeguarding and informing people about product quality.

According to Spence (1977) product failure itself is not sufficient to justify market intervention. However, the fact that consumers are not properly informed about the probability of failure attached to a given product calls for regulation. Spence explains that the authority can regulate the market in regard to product failure in three different forms. First, it can regulate the product directly. Second, it can provide information to consumers. Third, it can impose liability on the producer. 
Direct regulation of a product or service usually implies setting minimum quality standards and verifying that these standards are met by producers. For instance, in Mexico the federal government is in charge of these two tasks regarding alcohol consumption. On the one hand, the Secretaría de Salud issued norms 120 and 142 about alcoholic drinks and establishments that sell food and drinks, respectively. On the other hand, the regulatory agency that verifies that producers and products meet the standards is Comisión Federal para la Protección de Riesgos Sanitarios (COFEPRIS).

Despite direct product regulation, local authorities ban "all you can drink" arguing that it induces bars to serve low quality drinks. If this argument is true, there are at least a couple of reasons that justify the behavior of local authorities. First, it seems that direct regulation is not enough to protect consumers since COFEPRIS officials say that $40 \%$ of alcoholic drinks sold in Mexico do not satisfy the norm. ${ }^{2}$ Second, it is difficult for consumers and the authority to verify that drinks satisfy minimum quality standards, while it is relatively easy to verify that bars are not using promotions like "all you can drink". Finally, even if the argument is not true and local legislators know it, their real concern may be about excessive alcohol consumption, but prefer to be perceived as opposing low quality rather than alcohol consumption.

\section{Model}

There is a monopolist, who is able to choose between a two-part tariff or buffet pricing. The quality of the good produced by this firm is $s>0$. It is assumed that marginal costs are constant but depend on the pricing strategy and the quality of the good. Regardless of its pricing strategy the marginal cost of production for this firm is $c+s^{2}$. However, if the firm decides to charge customers a per-unit price, which is one of the elements of a two-part tariff, it must pay an additional marginal cost $c_{o}>0 .{ }^{3}$ Thus, the marginal cost associated to buffet pricing is $c+s^{2}$, while the marginal cost associated to per-unit pricing is $c_{o}+c+s^{2}$.

Consumers are identical, each of them with an individual demand given by the linear function $q(p, s)=s \cdot(\theta-p)$. Although the notation in this paper follows closely the one used in the literature on monopoly and quality, ${ }^{4}$ it is important to emphasize that this analysis is based on individual demands, while the work of Sheshinski (1976), Spence (1975) and Spence (1976) considers market demand functions. Parameter $\theta>0$ can be interpreted either as consumer's reservation price or appetite. Holding all other things constant, an increase in $\theta$ shifts out the individual's demand curve. This increases the consumer's reservation price and its consumption. Similarly, higher quality increases demand for the good. Finally, the price of the good is given by $p \geq 0$ and it is understood that buffet pricing implies $p=0$.

\footnotetext{
2 See the note: "Adulteradas, hasta $40 \%$ de las bebidas alcohólicas que se venden en el país" published by Alma E. Muñoz in the newspaper La Jornada in December 6, 2005.

3 As mentioned earlier in the document, in order to charge customers per-unit the firm needs to offer personalized attention.

4 As in Tirole (1988), quality is a characteristic of the good that increases its demand.
} 
It is important to note that the firm is able to choose quality regardless of the number of consumers it serves or the pricing strategy that is used by the firm. In other words, this analysis does not take into account that quality can be endogenous in this sense. For instance, it can be argued that the absence of waiters or the fact that consumers serve themselves makes buffet low quality. Similarly, it can also be argued, as in Becker (1991), that eating at restaurants is a social activity and, consequently, that consumers may prefer the ambience of a crowded restaurant than an empty one.

\subsection{Buffet pricing}

If the firm decides to use buffet pricing, it has to choose a fixed fee, $E$, taking into account that customers will consume until they are satiated. In this case, the monopolist will try to set $E$ as high as possible while satisfying the participation constraint. Thus the firm maximizes

$$
\pi_{b}(E, s)=E-\left(c+s^{2}\right) \cdot q(0, s) \text { subject to } \int_{0}^{q(0, s)} p(x, s) d x \geq E .
$$

This problem can be simplified solving the integral of the inverse demand function and substituting the demand function and the constraint into the equation. The profit function in terms of quality is given by

$$
\pi_{b}(s)=\frac{s \theta^{2}}{2}-\left(c+s^{2}\right) \cdot s \theta .
$$

The first term at the right-hand side of Eq. 2 is the buffet fee $E$, which is equivalent to the consumer's surplus. The second term is marginal cost times quantity considering that the individual consumes until satiation.

The first order condition for profit maximization is

$$
\frac{\partial \pi_{b}}{\partial s}=\frac{\theta^{2}}{2}-c \theta-3 s^{2} \theta=0 .
$$

The solution is

$$
s_{b}=\sqrt{\frac{\theta-2 c}{6}}
$$

Finally, maximized profits as a function of exogenous variables are given by

$$
\pi_{b}=\frac{\theta}{3 \sqrt{6}}(\theta-2 c)^{\frac{3}{2}}
$$




\subsection{Two-part tariff}

A two-part tariff combines a fixed fee and a per-unit price (Oi 1971). As explained in Nahata et al., buffet pricing is an extreme case of a two-part tariff where the per-unit price is equal to zero. If the firm uses a two-part tariff it chooses $E, p$ and $s$ to maximize

$$
\begin{gathered}
\pi_{t}(E, p, s)=E+p \cdot q(p, s)-\left(c+c_{o}+s^{2}\right) \cdot q(p, s) \text { subject to } \\
\int_{0}^{q(p, s)} p(x, s) d x \geq E+p \cdot q(p, s) .
\end{gathered}
$$

Again, this problem can be simplified solving the integral and substituting the participation constraint into the equation. The profit function in terms of production and quality is given by

$$
\pi_{t}(q, s)=\frac{q}{2} \cdot\left(2 \theta-\frac{q}{s}\right)-\left(c+c_{o}+s^{2}\right) \cdot q .
$$

The first order conditions for profit maximization are

$$
\frac{\partial \pi_{t}}{\partial q}=\theta-c-c_{o}-s^{2}-\frac{q}{s}=0
$$

and

$$
\frac{\partial \pi_{t}}{\partial s}=\frac{q^{2}}{2 s^{2}}-2 q s=0 .
$$

Solving the two equations simultaneously one obtains

$$
q_{t}=\frac{4}{5 \sqrt{5}}\left(\theta-c-c_{o}\right)^{\frac{3}{2}}
$$

and

$$
s_{t}=\sqrt{\frac{\theta-c-c_{o}}{5}} .
$$

Finally, maximized profits as a function of exogenous variables are given by

$$
\pi_{t}=\frac{8 \sqrt{5}}{125}\left(\theta-c-c_{o}\right)^{\frac{5}{2}}
$$


Fig. 1 Feasible costs set

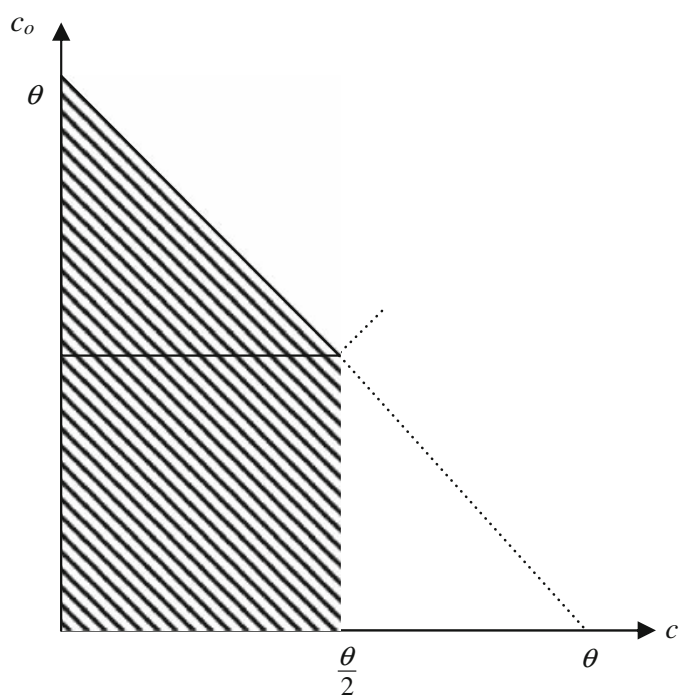

\section{Analysis}

None of the pricing strategies under analysis can be profitable if marginal costs are prohibitively high. It is straightforward to note from Eqs. 5 and 12 that two technical conditions must be satisfied for the two strategies to be profitable: $\theta>c+c_{o}$ and $\theta>2 c$. The first condition, which applies to per-unit pricing, says that production and transaction marginal costs cannot be higher than consumers' reservation price. The second condition, which is related to buffet pricing, says that the consumers' reservation price must be at least twice the size of the production marginal cost.

It is convenient to define a set of feasible transaction and production costs, $U=\left\{\left(c, c_{o}\right) \in \mathfrak{R}_{+}^{2}: c+c_{o}<\theta\right.$ and $\left.\theta>2 c\right\}$. That is, a set that contains all the points in the plane $\left(c, c_{o}\right)$ that satisfy the two technical conditions I mentioned in the previous paragraph. The shaded area in Fig. 1 represents this set.

I can also define $f(c): c \rightarrow c_{o}$ as the iso-quality and $g(c): c \rightarrow c_{o}$ as the iso-profit functions for a given $\theta>0$. The graphs of these functions in the plane $\left(c, c_{o}\right)$ represent points where the firm chooses equal quality or obtains equal profits, respectively, regardless of whether it uses a two-part tariff or buffet pricing. It follows from Eqs. 4 and 11 that

$$
f(c)=\frac{1}{6}(\theta+4 c) .
$$

Similarly, it follows from Eqs. 5 and 12 that

$$
g(c)=\theta-c-\left(\frac{125 \theta}{24 \sqrt{30}}\right)^{\frac{2}{5}}(\theta-2 c)^{\frac{3}{5}}
$$


Finally, it is worth showing that these functions have the following three properties:

Property $1 f(0)>g(0)$ for any $\theta>0$.

Proof It is not difficult to calculate

$$
f(0)=\frac{1}{6} \theta \text { and } g(0)=\left(1-\left(\frac{125}{24 \sqrt{30}}\right)^{\frac{2}{5}}\right) \theta \approx 0.02 \theta \text {. }
$$

Property $2 f\left(\frac{\theta}{2}\right)=g\left(\frac{\theta}{2}\right)$ for any $\theta>0$.

Proof It is not difficult to calculate

$$
f\left(\frac{\theta}{2}\right)=\frac{1}{2} \theta=g\left(\frac{\theta}{2}\right) .
$$

Property $3 f(c)$ is linear and $g(c)$ is convex for any

$$
c \in\left[0, \frac{\theta}{2}\right] .
$$

Proof Note that

$$
\frac{\partial f(c)}{\partial c}=\frac{2}{3}
$$

and

$$
\frac{\partial^{2} f(c)}{\partial c^{2}}=0
$$

while

$$
\frac{\partial g(c)}{\partial c}=-1+\left(\frac{125 \theta}{24 \sqrt{30}}\right)^{\frac{2}{5}} \frac{6}{5(\theta-2 c)^{\frac{2}{5}}}
$$

and

$$
\frac{\partial^{2} g(c)}{\partial c^{2}}=\left(\frac{125 \theta}{24 \sqrt{30}}\right)^{\frac{2}{5}} \frac{24}{25(\theta-2 c)^{\frac{7}{5}}}>0 .
$$

Figure 2 shows that the graphs of the iso-quality and iso-profit functions, $f$ and $g$ partition the feasible set, $U$, into three regions. Let $B$ be the region above the isoquality function, $M$ the region between the two functions and $T$ the region below the iso-profit function. 
Fig. 2 Graphs of the iso-quality and iso-profit functions, $f$ and $g$

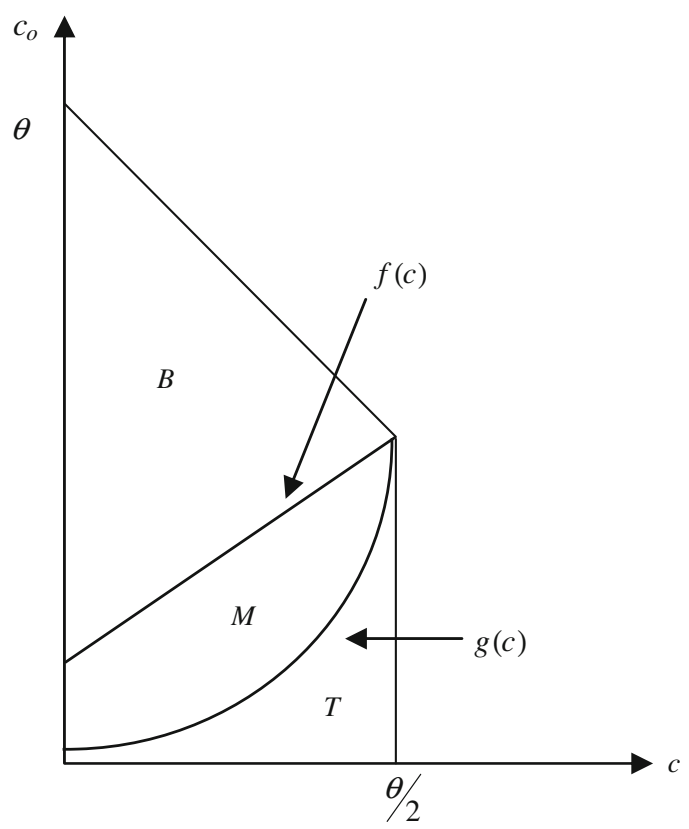

In this model, I try to relate the quality of the good that the monopolist produces with its pricing strategy choice. In order to establish the nature of this relationship, I will make two comparisons. First, I will compare the monopolist's maximized profits under the two pricing strategies that I consider in this paper. Afterwards, I will try to determine whether a monopolist using buffet pricing produces a higher or lower quality good than a monopolist using a two-part tariff.

Proposition 1 The monopolist obtains higher (or lower) profits when it chooses buffet pricing instead of a two-part tariff if $c_{o}>g(c)\left(\right.$ or $\left.c_{o}<g(c)\right)$.

Proof First I have to show that

$$
c_{o}>g(c)=\theta-c-\left(\frac{125 \theta}{24 \sqrt{30}}\right)^{\frac{2}{5}}(\theta-2 c)^{\frac{3}{5}}
$$

implies $\pi_{b}>\pi_{t}$. Note that

$$
c_{o}>\theta-c-\left(\frac{125 \theta}{24 \sqrt{30}}\right)^{\frac{2}{5}}(\theta-2 c)^{\frac{3}{5}}
$$

can be written, after some algebraic steps, as

$$
\left(\frac{125 \theta}{24 \sqrt{30}}\right)^{\frac{2}{5}}(\theta-2 c)^{\frac{3}{5}}>\theta-c-c_{o} .
$$


I can manipulate this expression to obtain

$$
\left(\frac{\theta}{3 \sqrt{6}}\right)(\theta-2 c)^{\frac{3}{2}}>\frac{8 \sqrt{5}}{125}\left(\theta-c-c_{o}\right)^{\frac{5}{2}} .
$$

It follows from Eqs. 5 and 12 that

$$
\pi_{b}=\left(\frac{\theta}{3 \sqrt{6}}\right)(\theta-2 c)^{\frac{3}{2}}>\frac{8 \sqrt{5}}{125}\left(\theta-c-c_{o}\right)^{\frac{5}{2}}=\pi_{t} .
$$

The same procedure can be used to show that $c_{o}<g(c)$ implies $\pi_{b}<\pi_{t}$.

This proposition is equivalent to the main result in Nahata et al. Of course, the intuitive explanation is also the same. Since the monopolist is able to avoid transaction costs by choosing buffet pricing instead of a two-part tariff, it follows that buffet is attractive from the firm's point of view if transaction costs are relatively high in comparison to production costs. On the contrary, a two-part tariff is more attractive than a buffet from the firm's perspective if production costs are relatively high in comparison to transaction costs because customers consume more when facing a buffet instead of paying for each unit. I can also explain the result in Proposition 1 using Fig. 2. If transaction and production costs fall in regions $B$ or $M$, the monopolist will choose buffet pricing. However, if the cost parameters fall in region $T$, the monopolist will rather choose a two-part tariff.

Proposition 2 The monopolist produces a higher (or lower) quality good when it chooses buffet pricing instead of a two-part tariff if $c_{o}>f(c)\left(\right.$ or $\left.c_{o}<f(c)\right)$.

Proof First I have to show that

$$
c_{o}>f(c)=\frac{1}{6}(\theta+4 c)
$$

implies $s_{b}>s_{t}$. Note that

$$
c_{o}>\frac{1}{6}(\theta+4 c)
$$

can be written, after some algebraic steps, as

$$
c_{o}>\theta-c-\frac{5}{6} \theta+\frac{10}{6} c \text {. }
$$

I can rearrange the terms to obtain

$$
\frac{\theta-2 c}{6}>\frac{\theta-c-c_{o}}{5}
$$


It follows from Eqs. 4 and 11 that

$$
s_{b}=\sqrt{\frac{\theta-2 c}{6}}>\sqrt{\frac{\theta-c-c_{o}}{5}}=s_{t} .
$$

The same procedure can be used to show that $c_{o}<f(c)$ implies $s_{b}<s_{t}$.

This proposition says that the relation between quality and the firm's pricing choice is ambiguous. Transaction and production costs are again crucial to determine whether a monopolist produces higher or lower quality goods when using buffet pricing instead of a two-part tariff. On the one hand, the monopolist offers a higher quality product when using buffet pricing instead of the alternative if transaction costs are relatively high in comparison to production costs. On the other hand, it offers a lower quality product if transaction costs are relatively low. Again, I can use Fig. 2 to clarify this result. If transaction and production costs fall in region $B$ a buffet pricing monopolist produces a higher quality good than a two-part tariff monopolist. However, if these parameters fall in regions $M$ or $T$, a two-part tariff monopolist produces a higher quality good than a buffet pricing monopolist.

The intuition behind this result is simple. A monopolist uses a two-part tariff or buffet pricing instead of a uniform price because these pricing strategies allow it to extract at least some part of consumer's surplus. By definition, a high quality good generates more surplus than a low quality good. It follows that a firm has more incentives to increase quality when it uses the pricing strategy that extracts more surplus and, consequently, generates more profits.

Figure 3 illustrates the effect of a quality increase under the two pricing strategies in the absence of transaction costs. The thick solid line is the demand curve of a representative individual, while the thick dotted line is the demand curve of the same individual for a higher quality good. Originally, a two-part tariff monopolist will set the fixed fee to extract all consumer's surplus (i.e., $\mathrm{A}+\mathrm{B}$ ) and the price equal to marginal cost (i.e., $c+s^{2}$ ). Thus profits equal $\mathrm{A}+\mathrm{B}$. On the other hand, the buffet pricing monopolist will set the fee equal to $\mathrm{A}+\mathrm{B}+\mathrm{C}+\mathrm{F}$ in order to extract all consumer surplus considering that customers eat or drink until satiation. It follows that under buffet pricing profits would be equal to $A+B-G$. Note that the inefficiency generated by buffet pricing is equal to $\mathrm{G}$. Furthermore, note that this inefficiency is the difference in profits between a two-part tariff and buffet pricing.

Now consider an increase in the quality of the good. The horizontal thin dotted line represents the new marginal costs. The profits of the firm using a two-part tariff would now be equal to $A+D$. It follows that increasing quality is profitable for the firm using this pricing strategy if $\mathrm{D}>\mathrm{B}$. That is, if the additional surplus generated by increasing quality compensates a higher marginal cost. In contrast, the profits of the firm using buffet pricing would be equal to $A+D-I$. Thus, the firm increases quality if $\mathrm{D}>\mathrm{B}+\mathrm{I}-\mathrm{G}$. Since higher quality products generate more consumption and higher marginal costs (that is, $\mathrm{I}>\mathrm{G}$ ), it follows that in the absence of transaction costs the two-part tariff monopolist produces a higher quality good and is more profitable than the buffet-pricing monopolist. 
Fig. 3 Demand curve and quality

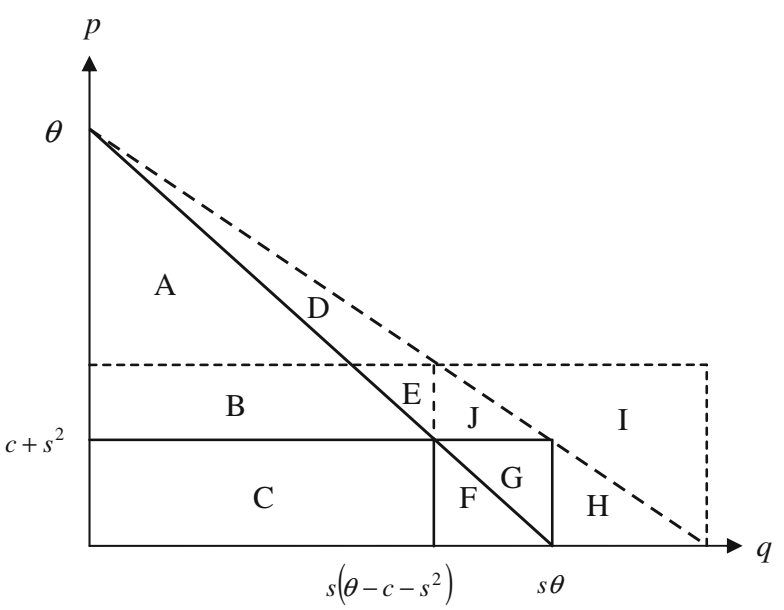

Since transaction costs are avoided by choosing buffet pricing, the quality choice and profits of a firm using this pricing strategy do not depend on transaction costs. On the other hand, a two-part tariff monopolist reduces quality and profits as transaction costs increase. Hence, the two-part tariff monopolist offers a lower quality good than a buffet pricing monopolist if transaction costs are sufficiently high.

At this point, it is convenient to summarize the results obtained so far. I can combine the two propositions and the properties of the iso-profit and iso-quality functions to write the following.

Theorem 1 The iso-profit and iso-quality functions, $g$ and $f$, respectively, partition the feasible set, $U$, into three regions, $B, M$ and $T$ in Fig. 2, such that

(i) if $\left(c, c_{o}\right) \in B$ then $\pi_{b}>\pi_{t}$ and $s_{b}>s_{t}$.

(ii) if $\left(c, c_{o}\right) \in M$ then $\pi_{b}>\pi_{t}$ and $s_{b}<s_{t}$.

(iii) if $\left(c, c_{o}\right) \in T$ then $\pi_{b}<\pi_{t}$ and $s_{b}<s_{t}$.

This theorem says that a buffet pricing monopolist is more profitable and offers a higher quality good than a two-part tariff monopolist when the cost parameters fall in region $B$. That is, when transaction costs are relatively high. It also says that a buffet pricing monopolist is more profitable but offers a lower quality good than a two-part tariff monopolist when the cost parameters fall in region $M$. Finally, it says that a two-part tariff monopolist is more profitable and offers a higher quality good than a buffet pricing monopolist when the cost parameters fall in region $T$. That is, when transaction costs are relatively low.

According to the main theorem of this paper buffet pricing is not necessarily associated with low quality goods. However, in certain cases it may lead to lower quality than the one that would be expected under a two-part tariff. Since profits drive the pricing strategy decision, regulators should not worry about quality if parameters fall in regions $B$ or $T$. In both cases, the more profitable strategy is associated with a higher quality good than the less profitable strategy. However, regulators may be concerned about quality if cost parameters fall in region $M$. In this particular case, a buffet pricing 
monopolist is more profitable and produces a lower quality good than a two-part tariff monopolist.

Although we should be concerned about quality when a monopolist uses buffet pricing, forbidding this practice is not necessarily a solution to the low quality problem. Indeed, under certain conditions it can have the opposite effect. Suppose that the authority decides to ban buffet pricing and then consider the effect of this restriction on quality in the three possible scenarios. If cost parameters fall in region $T$ the restriction is not relevant because the firm would freely choose a two-part tariff. On the other hand, if cost parameters fall in region $M$ the restriction would force the firm to choose a two-part tariff instead of buffet pricing and lead to higher quality goods. Finally, if parameters fall in region $B$, the restriction would force the firm to choose a two-part tariff instead of buffet pricing but lead to lower quality goods.

\section{Two consumer types}

I can extend the model to compare buffet pricing and two-part tariff strategies when there are different consumer types. Although this extension complicates the analysis, I must say in advance that the main results of the paper do not change. In order to keep the model tractable, I will consider two types of consumers equal in number but with different reservation prices or appetite for the good or service provided by the monopolist.

Assume that $\theta_{i}$ is the reservation price of consumer type $i(=1,2)$. With out loss of generality, suppose also that individual 1 is a low demand consumer, while individual 2 is a high demand consumer. Since the monopolist must choose whether to serve both consumer types or consumer type 2 only (that is, the high demand consumer), it is convenient to normalize the reservation price of consumer 1 to have $\theta_{1}=1$ and $\theta_{2}=\theta>1$. It follows that individual demand functions of consumers 1 and 2 would now be $q_{1}(p, s)=s \cdot(1-p)$ and $q_{2}(p, s)=s \cdot(\theta-p)$, respectively. Note that the analysis of the previous section applies directly to the case of a monopolist that serves only the high demand consumers. Thus, in the rest of this section I will consider a monopolist serving the two consumer types.

\subsection{Buffet pricing}

If the firm decides to use buffet pricing, it has to choose a fixed fee, $E$, taking into account that customers will eat until they are satiated. In this case, the monopolist will try to set $E$ as high as possible while satisfying the participation constraint of the low demand consumer. Thus the firm maximizes

$$
\begin{gathered}
\pi_{b}^{2}(E, s)=2 E-\left(c+s^{2}\right) \cdot\left(q_{1}(0, s)+q_{2}(0, s)\right) \text { subject to } \\
\int_{0}^{q_{1}(0, s)} p(x, s) d x \geq E .
\end{gathered}
$$


This problem can be simplified solving the integral and substituting the participation constraint and the demand function into the equation. It follows that

$$
\pi_{b}^{2}(s)=s-\left(c+s^{2}\right) \cdot s(1+\theta) .
$$

The first order condition for profit maximization is

$$
\frac{\partial \pi_{b}^{2}}{\partial s}=1-c \theta-3 s^{2}-3 s^{2} \theta=0
$$

The solution is

$$
s_{b}=\frac{1}{\sqrt{3}} \sqrt{\frac{1}{1+\theta}-c} .
$$

Finally, maximized profits as a function of exogenous variables are given by

$$
\pi_{b}^{2}=\frac{2 \sqrt{3}(1+\theta)}{9}\left(\frac{1}{1+\theta}-c\right)^{\frac{3}{2}}
$$

\subsection{Two-part tariff}

If the firm decides to charge customers a two-part tariff, it chooses $E, p$ and $s$ taking into a account that the low demand consumer must be willing to participate. That is, the monopolist maximizes

$$
\begin{aligned}
\pi_{t}^{2}(E, p, s)= & 2 E+p \cdot\left(q_{1}(p, s)+q_{2}(p, s)\right) \\
& -\left(c+c_{o}+s^{2}\right)\left(q_{1}(p, s)+q_{2}(p, s)\right) \\
& \text { subject to } \int_{0}^{q_{1}(p, s)} p(x, s) d x \geq E+p \cdot q_{1}(p, s) .
\end{aligned}
$$

Again, this problem can be simplified solving the integral and substituting the participation constraint and the demand function into the equation. It follows that

$$
\pi_{t}^{2}(q, s)=s(1-p)^{2}+\left(p-c-c_{o}-s^{2}\right) s(\theta+1-2 p) .
$$

The first order conditions for profit maximization are

$$
\frac{\partial \pi_{t}^{2}}{\partial p}=s\left(2 c-1-2 p+\theta+2 c_{o}+2 s^{2}\right)=0
$$


and

$$
\begin{aligned}
\frac{\partial \pi_{t}^{2}}{\partial s}= & p-c+2 c p-c \theta+p \theta-c_{o}+2 p c_{o}-\theta c_{o}-2 p^{2}-3 s^{2}+6 p s^{2}-3 s^{2} \theta \\
& +(1-p)^{2}=0
\end{aligned}
$$

In order to simplify the price, quality and profits expressions, I can set $\phi\left(c, c_{o}, \theta\right)$ in terms of exogenous variables as follows

$$
\phi\left(c, c_{o}, \theta\right)=\sqrt{11+10 \theta-5 \theta^{2}+16 \cdot\left(c+c_{o}\right) \cdot\left(c+c_{o}-2\right)} .
$$

Solving Eqs. 22 and 23 simultaneously I obtain

$$
p_{t}=\frac{4 \cdot\left(c+c_{o}\right)+5 \theta+1-\phi}{10}
$$

and

$$
s_{t}=\sqrt{\frac{6 \cdot\left(1-c-c_{o}\right)-\phi}{10}} .
$$

Finally, maximized profits are given by

$$
\begin{aligned}
\pi_{t}^{2}= & \frac{8 \cdot\left(c+c_{o}\right) \cdot\left(c+c_{o}-2\right)-10 \theta+5 \theta^{2}+13+2 \cdot\left(1-c-c_{0}\right) \cdot \phi}{25} \\
& \times \sqrt{\frac{6 \cdot\left(1-c-c_{o}\right)-\phi}{10}} .
\end{aligned}
$$

\subsection{Analysis}

The first step in the analysis is to define a set of feasible transaction and production costs considering that the two consumer types are served under both pricing schemes. Formally, the feasible set is $U_{2}=\left\{\left(c, c_{o}\right) \in \Re_{+}^{2}: \pi_{b}^{2}>\pi_{b}\right.$ and $\left.\pi_{t}^{2}>\pi_{t}\right\}$. In other words, a set that contains all the points in the plane $\left(c_{o}, c\right)$ such that serving two consumer types is more profitable than serving only one consumer type under both pricing schemes. The second step is to define the iso-quality and iso-profit functions, considering that the firm serves both consumer types. Let $f_{2}(c): c \rightarrow c_{o}$ be the iso-quality and $g_{2}(c): c \rightarrow c_{o}$ the iso-profit functions, respectively.

Since Eqs. 5 and 19 are relatively simple, I can calculate the border of the feasible set where profits are higher serving two consumer types than one consumer type under buffet pricing. That is, 
Fig. 4 Graphs of the iso-quality and iso-profit functions for $\theta=1.1$

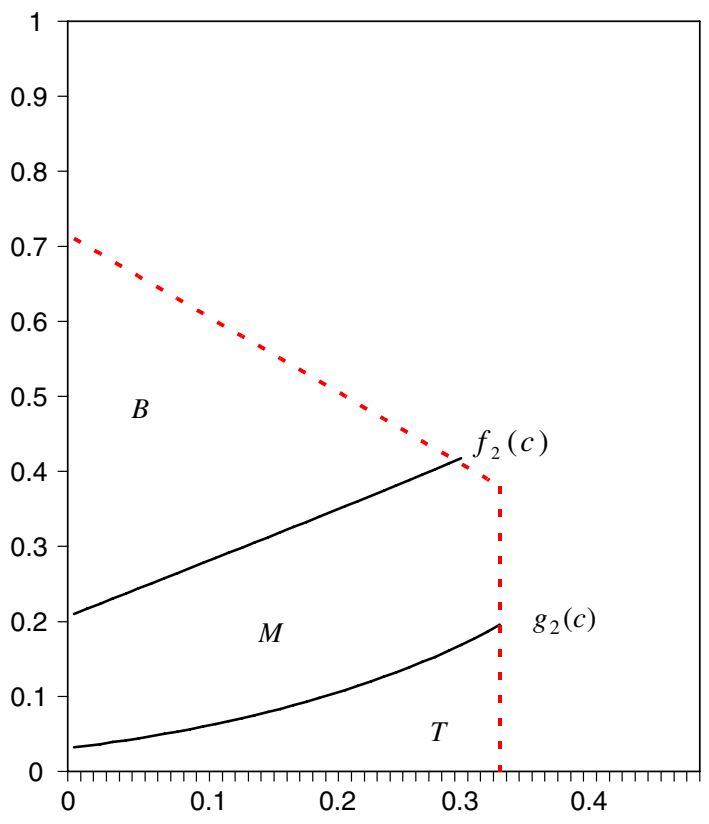

$$
c \leq \frac{\left(\frac{\sqrt{18} \cdot \theta}{12 \cdot(1+\theta)}\right)^{\frac{2}{3}} \cdot \theta-\frac{1}{1+\theta}}{2 \cdot\left(\frac{\sqrt{18} \cdot \theta}{12 \cdot(1+\theta)}\right)^{\frac{2}{3}}-1}
$$

Similarly, I can use Eqs. 18 and 26 to calculate the iso-quality function

$$
f_{2}(c)=1-\frac{1}{1+\theta}-\frac{1}{2} \sqrt{2 \theta-\theta^{2}+\frac{16}{9}\left(\frac{1}{1+\theta}-c\right)^{2}-1}
$$

On the other hand, due to the complexity of Eq. 27 I will compute the graph of the other border of the feasible set and the graph of the iso-profit function, $g_{2}(c)$, numerically for a given $\theta$.

Figure 4 shows that the graphs of the iso-quality and iso-profit functions, $f_{2}$ and $g_{2}$ partition the new feasible set, $U_{2}$, into three regions for $\theta=1.1$. The dotted lines are the borders of the feasible set. Keeping the notation used in the previous analysis, $B$ is the region above the iso-quality function, $M$ the region between the two functions and $T$ the region below the iso-profit function.

Note that the main theorem of the paper applies when the firm serves two consumer types, at least for certain values of parameter $\theta$. Again, this theorem says that a buffet pricing monopolist is more profitable and offers a higher quality good than a two-part tariff monopolist when the cost parameters fall in region $B$. It also says that a buffet pricing monopolist is more profitable but offers a lower quality good than a two-part 
tariff monopolist when the cost parameters fall in region $M$. Finally, it says that a two-part tariff monopolist is more profitable and offers a higher quality good than a buffet pricing monopolist when the cost parameters fall in region $T$.

\section{Conclusions}

In this paper, I elaborated a model to determine whether a monopolist produces higher or lower quality goods when using buffet (all you can drink) pricing instead of a twopart tariff. According to the main theorem of this paper buffet pricing is not necessarily associated with low quality goods. It turns out that the relation between transaction and production costs is crucial to determine which pricing strategy leads the firm to produce higher quality goods. If I compare the quality of the products under buffet pricing and a two-part tariff, I find that the monopolist offers a higher quality product when using buffet pricing if transaction costs are relatively high in comparison to production costs. On the other hand, it offers a lower quality product if transaction costs are relatively low.

Usually the more profitable strategy is associated with a higher quality good than the less profitable strategy. Since profits drive the pricing strategy decision, it follows that regulators should not worry about quality most of the times. However, under certain cost conditions buffet pricing is more profitable and leads to lower quality goods than a two-part tariff. Bars offering "all you can drink", the case that motivated this paper, appears to be a good example illustrating lower quality under buffet pricing. Since transaction costs are relatively low in comparison to production costs, the main result of the paper suggests that bars offer low quality drinks when they use "all you can drink" specials. Banning "all you can drink" may be justified if it is difficult for the authority to regulate quality directly or the consumer is not well informed about the quality of drinks. For instance, if bars tend to serve non-bottled alcoholic drinks when they use this type of promotion.

Although this "all you can drink" case suggests that there should be a concern about quality, forbidding the practice is not necessarily a solution to the low quality problem. Indeed, in certain cases it can have the opposite effect.

Acknowledgements I would like to thank the editor and two anonymous referees for their help and valuable comments.

\section{References}

Anderson, R., \& Enomoto, C. (1987). Product quality regulation: A general equilibrium analysis. Canadian Journal of Economics, 20(4), 735-749.

Barro, R., \& Romer, P. (1987). Ski-lift pricing, with applications to labor and other markets. American Economic Review, 77(5), 875-890.

Becker, G. (1991). A note on restaurant pricing and other examples of social influences on price. Journal of Political Economy, 99(5), 1109-1116.

Besanko, D., Donnenfeld, S., \& White, L. (1987). Monopoly and quality distortion: Effects and remedies. Quarterly Journal of Economics, 102(4), 743-768.

Buchanan, J. (1965). An economic theory of clubs. Economica, 32(125), 1-14.

Nahata, B., Ostaszewski, K., \& Sahoo P. (1999). Buffet pricing. Journal of Business, 72(2), 215-228. 
Oi, W. (1971). A disneyland dilemma: Two-part tariffs for a mickey mouse monopoly. Quarterly Journal of Economics, 85(1), 77-96.

Oi, W. (1973). The economics of product safety. Bell Journal of Economics, 4(1), 3-28.

Sheshinski, E. (1976). Price, quality and quantity regulation in monopoly situations. Economica, 43(170), 127-137.

Spence, M. (1975). Monopoly, quality and regulation. Bell Journal of Economics, 6(2), 417-429.

Spence, M. (1976). Product differentiation and welfare. American Economic Review, 66(2), 407-414.

Spence, M. (1977). Consumer misperceptions, product failure and producer liability. Review of Economic Studies, 44(3), 561-572.

Tirole, J. (1988). The theory of industrial organization. Cambridge, MA: MIT Press.

Weisman, D. (2005). Price regulation and quality. Information Economics and Policy, 17(2), 165-174. 